\title{
Raising the Curtain on Drama Therapy: Healing Benefits for Youth and Older Adults
}

\author{
Vanessa C. Boila1, Lanette W. Klettke², Stephanie J. Quong3, \& Ciara A. Gerlitz ${ }^{4}$
}

\author{
Review Editors \\ Ava Padfield ${ }^{3}$, Trish Carmody5 ${ }^{5}$ Mitch Clark6 ${ }^{6}$, Taylor Chomiak ${ }^{6}$, Alain Morin 6 \\ Editor \\ Shayla-Rose Somers ${ }^{7}$
}

\begin{abstract}
The vast majority of people around the world have been exposed to dramatic arts in some way, shape, or form, but only recently has drama therapy been accepted as a therapeutic treatment for individuals across the lifespan. This paper provides a general introduction to drama therapy and some of the techniques (e.g., role playing and storytelling) employed in its delivery and hands-on practice. In addition, the paper explores how drama therapy has been used to treat young people (approximately 10-17 years old) who have autism and/or social, emotional, and behavioural difficulties, and older adults (approximately 60-90 years old) who are experiencing normative or non-normative aging. The findings presented here suggest drama therapy may be an efficacious, healing treatment for a myriad of age groups. For instance, its positive effects on individuals with dementia have been observed, and an assortment of intra- and inter-personal improvements have been documented in youth. Considering drama therapy is still a growing field, less drama therapy research exists in comparison to its alternative treatments.
\end{abstract}

Keywords: drama therapy, youth, older adults

\footnotetext{
$\mathbf{1}$ MEd Student $\cdot$ Department of Educational Psychology $\cdot$ University of Alberta $\cdot$ Original manuscript written during undergraduate enrolment at Mount Royal University · boila@ualberta.ca

2 JD · Queen's University

3 BA Psychology · Mount Royal University

4 BA Psychology (Minor: Sociology) · Mount Royal University

5 BA Psychology (Minor: Anthropology) · Mount Royal University

$6 \mathrm{PhD} \cdot$ Department of Psychology $\cdot$ Mount Royal University

7 BA Psychology (Minors: Women \& Gender Studies; Biology) · Mount Royal University
}

Copyright (C) 2020 Vanessa C. Boila, Lanette W. Klettke, Stephanie J. Quong, and Ciara A. Gerlitz This is an open-access article distributed under the terms of the Creative Commons Attribution 3.0 License. The use, distribution or reproduction of this article is permitted if the original copyright holder is credited, a link to the license is provided and changes to original material are indicated. 


\section{Raising the Curtain on Drama Therapy: Healing Benefits for Youth and Older Adults}

Gone are the days when psychotherapy strictly meant sitting in an armchair talking aloud to someone across from you. Artistic expression has seeped into the world of therapy by creating a unique blend of uninhibited creativity and systematic techniques. Among a wide range of therapeutic techniques, drama therapy is a commonly used form of art therapy (Jennings, 1990). Although drama therapy has only been accepted as a scientifically based form of therapy more recently, societies around the world have been reaping the benefits of drama for thousands of years (Armeniox, 2015).

In fact, Armeniox's (n.d.) Linkedin page showcases her many prominent roles such as that of counsellor, educator, and clinical supervisor, and documents her applied experiences using creative psychotherapies; as such, she has much knowledge to offer and her voice is very important within the realm of creative art therapies. Armeniox (2015) suggested that drama therapy, which is a subsection of art therapy, involves using theatrics as a mode of healing.

Moreover, the drama therapy process uses various techniques such as role play, storytelling, scripts, improvisation, enactment, externalization, and performance, which are often carried out in a group setting (D'Amico et al., 2015; Jaaniste et al., 2015). During the therapeutic process, individuals are asked to acquire a role (e.g., a parent, teacher, friend, or historical figure) that they act out for healing purposes (Armeniox, 2015). Therapists themselves may also choose to acquire a role that the clients can interact with; naturally, a safe space for growth is created (Bassingthwaighte, 2017).

Although the nature of drama therapy allows for much flexibility within its practice, a warm-up, a main activity, and a cool down are generally incorporated (Lewis \& Banerjee, 2013). This article seeks to explore drama therapy in a holistic manner by: (1) examining how this therapeutic technique can help younger generations; and (2) exploring the implications drama therapy has for improving the lives of older people.

\section{Drama Therapy and Young People}

Within the last decade, various studies exploring the role of drama therapy and its implications on young people (individuals ranging from approximately age 10-17 years old) with autism spectrum disorder (ASD) have begun to emerge. This brain-based disorder is associated with symptoms that vary greatly from one person to the next (e.g., communication difficulties, impaired social skills, repetitive behaviours, and selective interests) (Government of Canada, 2018).

D'Amico et al.'s (2015) year-long drama intervention for young people with ASD involved making inner experience visible, developing imaginary worlds, role playing, and storytelling.; parental ratings also suggested improvements in engagement, externalizing, and problem behaviours (D'Amico et al., 2015). Results showed increased attentiveness, and (according to parental and student ratings) improvements in hyperactivity and inattention were also found (D'Amico et al., 2015). Therefore, drama therapy may be particularly efficacious for treating behavioural and inattentional problems

Similarly, Godfrey and Haythorne (2013) collected feedback from parents, caregivers, and teachers in their study, and they examined opinions (i.e., thoughts about the effect of drama therapy on a participant during and after the therapy sessions, and within the home and school environment) of a drama therapy treatment for young people with ASD.

Themes, such as openness to exploration, building a supportive peer network, social skill development, and anxiety reduction whilst increasing self-confidence emerged. As such, drama therapy may not have a singular benefit; rather, multiple modalities in smaller-scale, semi-controlled studies, such as Godfrey and Haythorne (2013). are associated with several positive outcomes.

Unlike D'Amico et al.'s (2015) broad approach, Lewis and Banerjee (2013) focused precisely on using storytelling in drama therapy 
with three young individuals with ASD, and the following was noted: one individual expressed emotion more constructively, another demonstrated increased cooperation, and the third participant showcased strengths and creativity.

In addition, Lewis and Banerjee (2013) suggested storytelling may be more salient than other drama therapy practices (e.g., roleplaying), and drama therapy may benefit individuals with ASD in a unique way; still, a stirring curiosity may linger regarding the benefits drama therapy may have for young people who experience challenges other than ASD.

Since young individuals with ASD often reap positive outcomes from drama therapy, a researcher proposed if youth with social, emotional, and behavioural difficulties (SEBD) along with mental health issues reap similar benefits from drama therapy.

To explore this, Cobbett's (2016) mixedmethod study at SEBD schools assessed the efficacy of music therapy, drama therapy, and art therapy. Compared to a control group, Cobbett (2016) observed a significant improvement in SEBD for the students receiving the arts therapy, yet interviews conducted with some students revealed even more therapeutic advantages.

For instance, perceptions of increased confidence, better emotional regulation, feelings of tranquility, reports of catharsis, an appreciation for being understood without having to directly state a problem, and the ability to work through difficulties in a relaxed setting that felt less like therapy and more like a fun, engaging environment were reported (Cobbett, 2016). With this in mind, drama therapy combined with other arts therapies may one day become the norm rather than the exception for helping individuals with ASD and youth with other personal struggles.

Intriguingly, Bassingthwaighte (2017) is now extending the practice of drama therapy by conducting therapy in natural outdoor environments such as parks, school playgrounds, or even school gardens. When Bassingthwaighte (2017) interviewed drama therapists about drama therapy in the natural environment for young people with social, emotional, and mental health issues, not only did she observe greater authenticity in therapy, but the outside environment enhanced the use of symbolism and metaphor thereby giving rise to working through problems at an accelerated rate.

This seems to suggest that the environment drama therapy is conducted in, especially for individuals with mental health issues or SEBD, may be equally important, if not more important perhaps, than drama therapy itself.

\section{Drama Therapy and Older Adults}

Few studies have been conducted around drama therapy and older adults (i.e., individuals ranging from approximately 60-90 years old), but in the past decade new research has started to emerge.

A study conducted by Keisari and Palgi (2017) combined the use of life-crossroads (i.e., memories and/or events that have significantly affected an individual) and drama therapy to examine mental well-being in a normativeaging population. In this study, participants completed a life-review (i.e., thinking about important events that have occurred throughout life); additionally, psychodrama techniques were incorporated into the lifereview process.

Interestingly, the life-review process, based on Keisari and Palgi's (2017) viewpoint, has helped individuals reflect on and accept past experiences, both positive and negative; more precisely, the therapeutic process used by the authors consisted of 12 sessions, and the sessions were partitioned into several stages.

Firstly, participants identified their life crossroads (e.g., autobiographical memories, meaningful life experiences, and important life changes or life decisions). Secondly, participants shared their life-crossroads with each other and acted them out on stage. Thirdly, participants classified the main roles in their life-crossroad stories (e.g., father, student, daughter, son, or teacher).

After identifying these roles, participants reflected on the diverse identities they had already assumed and considered future roles to 
explore. Through this process, older adults were able to give new meaning to their lifecrossroads; furthermore, participants were able to improve their intra- and interpersonal motivations.

In order to gain new perspectives and insights, participants in the study were also given the choice to examine and alter elements of their life-crossroads. Next, the older adults created subsequent life-crossroads that were worked through on a performance stage. Finally, using any art medium of their choice, participants shared their individual experience with the life-review and psychodrama process through a stage performance.

When Keisari and Palgi (2017) integrated drama therapy components with a life-review in the study, participants reported increased imaginative and creative abilities, and the increased capacity to explore life from differing perspectives. Overall, findings asserted that the therapeutic process strengthened psychological health, self-acceptance, and meaning in life (Keisari and Palgi, 2017).

Throughout the dramatic process not only did each participant have a role to play, but participants engaged cognitively, behaviourally, and emotionally in their roles; the drama therapy aspect of the process helped to further reinforce social interactions and relationships.

In the process outlined by Keisari and Palgi (2017), older adults were able to envision how others perceive them, and the process encouraged the growth of interpersonal relationships. Therefore, meaningful social supports can assist older adults by increasing their ability to cope with stressors and by paving the way for a successful aging experience.

On the other hand, it is commonly known that dementia can occur in older adults; consequently, determining efficacious therapies for treating a global, non-normative aging population is critical. Jaaniste et al. (2015) suggested that dementia can cause confusion in an individual's life and in their identity.

In this study, Jaaniste et al. (2015) analyzed the impact of drama therapy on the overall quality of life (QoL) of older adults with "mild to moderate dementia" (p. 42). In the beginning stages of dementia there are noticeable changes in behaviour, mood, and personality; complications can be further exacerbated by a decline in cognitive functioning (Coulson et al., 2002). Jaaniste et al. (2015) formed their definition of dementia from Coulson et al.'s (2002) understanding of the disease; thus, dementia was defined as progressive worsening of complex brain functions.

In Jaaniste et al.'s (2015) study, each therapy session started with activities and games, which helped build social relationships with other participants. The activities in the study involved the following: storytelling; humour; photographs; role playing; and improvisation. During storytelling, some participants portrayed their story using body language instead of words.

To expand on this notion, when participants communicated or acted out their stories during this study, they indicated achievement of closure by resolving negative feelings associated with life-altering events. Humour was also used when participants talked and joked about their level of awareness and the severity of their dementia. This may have accounted for an increase in QoL, though no precise conclusions were drawn from the researchers regarding the relationship between humour and QoL.

What is more, older adults with dementia in the study examined photograph collections that both depicted different emotions, and represented their own personal feelings about a memory, after which participants selected photos that they felt were most representative of their situation. In working with the photos, some participants were more willing to engage in dramatic enactments and the therapeutic process. Role playing and improvisation were also facilitated by the researchers when individuals acted out chosen memories. In working together to act out and explore these memories, the participants improved their social relationships with others.

The participants in this study who actively engaged in the therapeutic process expressed 
their emotions more effectively, shared unresolved inner conflicts, improved QoL, gained more decision-making power, and increased their self-confidence. Therefore, drama therapy may help older adults with dementia cope with daily struggles and become more content with life.

Like their normative aging peers, the participants were able to experience the loss of a loved one, isolation (whether by choice or social exclusion), and negative emotions (e.g., anger or sadness). Because drama therapy is used for both normative and non-normative aging populations, it may be an efficacious therapeutic option for older adults with dementia.

Following these findings, drama therapy may become more widespread in years to come. A recommendation for future research is to draw further distinctions between using drama therapy to improve overall QoL, versus using it to heal the dementia itself.

\section{Conclusion}

With these considerations, drama therapy can enhance the lives of many individuals. Adding meaning and/or quality to life as well as increasing social supports for older generations are just some of the many benefits drama therapy has to offer (Keisari \& Palgi, 2017). In the same fashion, drama therapy has been shown to help younger individuals overcome some symptoms of SEBD (Cobbett, 2016). However, as drama therapy is still a growing field, there are limitations that come with it.

Landy (2006), a drama therapist, has consistently argued that the practice still has a long way to go. He indicates that this type of therapy requires a lot more to be on par with older, well-established therapeutic methods. Because drama therapy is still in its infancy, Landy has suggested that drama therapy practitioners should take a long look in the mirror and accept its pitfalls; namely, a lack of research, lack of conversations concerning ethics, and the inability of some therapists to work together in a cohesive unit.

More recently, to better understand the effectiveness of drama therapy research, Armstrong et al. (2019) examined peer- reviewed drama therapy articles and reoccurring themes found within them to explore the effectiveness of drama therapy.

Staggeringly, almost three quarters of the studies Armstrong et al. (2019) examined had fewer than 20 participants, much of the research was considered preliminary, and they noted a problematic trend of numerous pilot studies and case studies. Additionally, no singular theme or focal point could be identified by the researchers, though the findings suggested drama therapy can decrease undesired symptoms and improve wellness.

Ultimately, Armstrong et al. (2019) concluded future of drama therapy research should aim to use operational definitions for therapeutic processes, that large-sample quantitative research should be used more than qualitative research, and that outcome variables linked to therapeutic effectiveness are needed. All in all, like Landy's sentiments in 2006, drama therapy is a growing field with a long way to go to become more empirically sound.

\section{References}

Armeniox, L. (2015). Drama therapy. In E. Neukrug (Ed.), The SAGE encyclopedia of theory in counseling and psychotherapy, 302-306. https://doi.org/10.4135/9781483346 502.n108

Armeniox, L. [Leslie]. (n.d.). Profile [Linkedin page]. Retrieved February 1, 2020, from https://www.linkedin.com/in/lesliearmeniox-1423b116

Armstrong, C. R., Frydman, J. S, \& Wood, S. (2019). Prominent themes in drama therapy effectiveness research. Drama Therapy Review, 5, 173-216. https://doi.org/10.1386/dtr_00002_1. Bassingthwaighte, L. (2017). Taking dramatherapy into the outside space the benefits and obstacles when working with children with SEMH issues. Dramatherapy, 38, 16-31. 
https://doi.org/10.1080/02630672.20 17.1291846

Cobbett, S. (2016). Reaching the hard to reach: A quantitative and qualitative evaluation of school-based arts therapies with young people with social, emotional, and behavioural difficulties. Emotional and Behavioural Difficulties, 21, 403-415. https://doi.org/10.1080/13632752.20 16.1215119

Coulson, B., Fenner S., \& Almeida, O. (2002). Successful treatment of behavioural problems in dementia using a cholinesterase inhibitor: The ethical questions. Australian \& New Zealand Journal of Psychiatry, 36, 259-262. https://doi.org/10.1046/j.14401614.2002.00977.x

D’Amico, M., Lalonde, C., \& Snow, S. (2015). Evaluating the efficacy of drama therapy in teaching social skills to children with autism spectrum disorders. Drama Therapy Review, 1, 21-39. https://doi.org/10.1386/dtr.1.1.21_1

Godfrey, E., \& Haythorne, D. (2013). Benefits of dramatherapy for autism spectrum disorder: A qualitative analysis of feedback from parents and teachers of clients attending Roundabout dramatherapy sessions in schools. Dramatherapy, 35, 20-28. https://doi.org/10.1080/02630672.20 13.773131
Government of Canada. (2018). About autism spectrum disorder (ASD). Retrieved February 1, 2020, from https://www.canada.ca/en/publichealth/services/diseases/autismspectrum-disorder-asd/about-autismspectrum-disorder-asd.html

Jaaniste, J., Linnell, S., Ollerton, R. L., \& SlewaYounan, S. (2015). Drama therapy with older people with dementia-Does it improve quality of life? The Arts in Psychotherapy, 43, 40-48. https://doi.org/10.1016/j.aip.2014.12. 010

Jennings, S. (1990). Dramatherapy with families, groups, and individuals: Waiting in the wings. London, UK: Jessica Kingsley Publishers.

Keisari, S., \& Palgi, Y. (2017). Life-crossroads on stage: Integrating life review and drama therapy for older adults. Aging \& Mental Health, 21, 1079-1089. https://doi.org/10.1080/13607863.20 16.1199012

Landy, R. (2006). The future of drama therapy. The Arts in Psychotherapy, 33, 135-142. https://doi.org/10.1016/j.aip.2005.10. 003

Lewis, J., \& Banerjee, S. (2013). An investigation of the therapeutic potential of stories in drama therapy with young people with autistic spectrum disorder. Dramatherapy, 35, 29-42. https://doi.org/10.1080/02630672.20 13.772456 